\title{
The stability study of goaf based on C-ALS data point cloud and FLAC ${ }^{3 D}$ Coupled modeling
}

\author{
Jia Huihui ${ }^{1,2^{*}}$, Xue Jianzhi ${ }^{1}$ \\ ${ }^{1} 514$ Brigade of North China Geological Exploration Bureau, Chengde, Hebei, 067000 \\ ${ }^{2}$ EDP Sciences, Production Department, 91944 Les Ulis Cedex A, France
}

\begin{abstract}
Through drilling and three-dimensional scanning by C-ALS laser, the spatial position and size of mined-out area can be obtained. It can provide important technical basis for safety management and evaluation of goaf. This paper takes the stability analysis of Hidden Goaf in the third mining area of Zhoutaizi Iron Mine, Zhangbaiwan town, Luanping County as an example. After the mined-out area was drilled, the data point cloud was obtained by $\mathrm{C}$-als three-dimensional Laser scanning and the three-dimensional visualization model was constructed. Write the conversion program in FISH language and import it into FLAC3D, The distribution characteristics of ground pressure, deformation, failure of surrounding rock and surface subsidence in goaf are analyzed. And it is consistent with the actual situation of the goaf, Thus it shows the feasibility of the coupling modeling technology method of C-ALS data point cloud and FLAC3D in obtaining three-dimensional feature information of goaf and determining the stability of goaf. At the same time it provides technical reference for prospecting and stability analysis of similar goaf.
\end{abstract}

\section{Introduction}

Mined-out area formed by underground mining of metal and non-metal mines is an important work of mine safety management. Strengthening the monitoring and early warning of goaf is an important means to avoid the goaf collapse disaster. For the historical goaf in the mining area, due to the lack of abovehole and underground comparison map and plane location map, how to effectively explore the space position and three-dimensional shape of the goaf and establish its three-dimensional visualization model is one of the important basic work to effectively realize the safety management and evaluation of the goaf. At present the detection technology of goaf at home and abroad mainly includes engineering drilling, geophysical exploration, 3D laser detection and so on, The main goaf laser detection equipment includes CMS(cavity monitoring system) produced by Optech Company of Canada and C-ALS(cavity auto scanner laser system) produced by MD Company of Britain, Based on the principle of laser ranging, they obtain a large number of point cloud data of goaf boundary through rotating scanning head, and output three-dimensional coordinate information of scanning points through processing software. For the exploration of the goaf which cannot be accessed by human, it mainly relies on manual single point survey, engineering drilling and geophysical method integrated geophysical exploration technology, Because the effective data obtained by single point survey and engineering drilling are often less, it is difficult to collect the complex morphological characteristics of goaf. Due to the complexity of goaf geological conditions and the interference of external factors, it is difficult for geophysical methods to detect the accurate shape and scale of goaf, and the visualization effect of geophysical methods is poor. Based on the C - ALS detection point cloud data after removing abnormal points, coordinate conversion processing to generate empty area data points, written by FISH language conversion program into calculating program FLAC3D in luanping Zhang Baiwan town weeks counter concealed goaf stability analysis of three iron ore mining area, for the next goaf filling mining management provides the technical basis.

\section{C-ALS 3D Laser Scanning System}

\subsection{The working principle}

At the same time, the protection of the hole wall of the drilling hole is well done. During the measurement, the probe is placed into the goaf through the connecting rod for measurement. The front end of the system probe is the video surveillance camera and the side of the lighting system is the laser transmitting and receiving system. The three-dimensional laser scanning system is placed inside the cavity structure to be measured, and the laser pulse emitter and laser TX and laser RX mirrors built in the system are rotated in a fast and orderly manner according to the specified mode. The narrow beam laser pulses scan the measured area according to the rotation mode in a certain rule. By calculating the time that the laser pulse of each measuring point in the scanning area passes from

* Corresponding author: magic-jia@163.com 
being excited to the surface of the measured object and then returning to the receiving system, the system encoder calculates and measures the transmitting Angle of each pulse, and then calculates the three-dimensional coordinate information of the measured space structure, Its basic working principle is shown in the figure 1 .

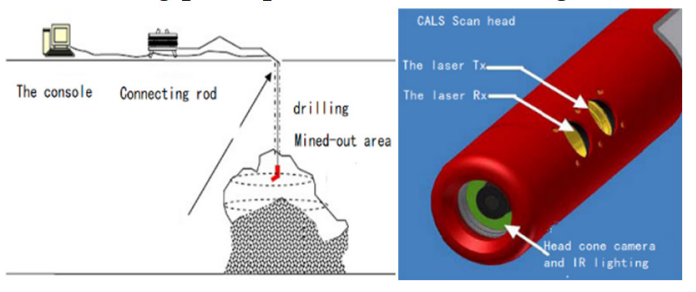

Fig. 1.The indication of C-ALS point cloud data detection

\subsection{Scanning way}

Before the measurement, the 3D laser scanning system first carries out a self-check to the position, so as to ensure the precise movement in the measurement process. To start the measurement, the probe is opened $90^{\circ}$ to the left(The system defaults to $180^{\circ}$ ), At this time, the end camera points to one side of the space structure, the laser transceiver system points to the bottom, and the bottom is scanned at this time. During the measurement, the probe is gradually opened, eventually pointing $90^{\circ}$ to the right(The system defaults to $180^{\circ}$ ), At this time, the end camera points to the other side of the space structure, and the laser transceiver system points to the upper part to scan the top part. During the opening process from $0^{\circ}$ to $180^{\circ}$, the probe rod rotates horizontally to scan at $360^{\circ}$, and the probe moves $1^{\circ}$ (or $3^{\circ}$, depending on the detection accuracy) after each $360^{\circ}$ full horizontal scan. The next horizontal scan is performed until all probes are opened from $0^{\circ}$ to $180^{\circ}$, Complete the full space scan from top to bottom, The scanning mode is shown in the figure 2.

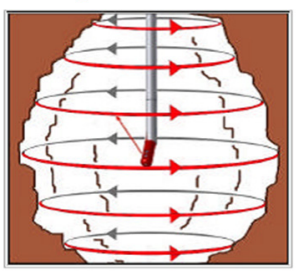

Horizontal sweep mode

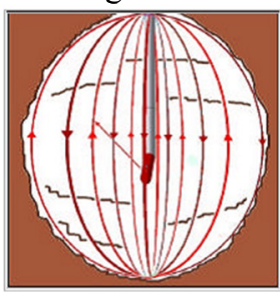

Vertical sweep mode
Fig. 2. C-ALS scanning pattern

\section{Project summary}

Due to many years of mining in Zhoutaizi Iron Mine in Zhangbaiwan Town, Luanping County, Hebei Province, a large number of shallow buried goafs have been left behind by history, and some of them have undergone obvious ground collapse. On August 14, 2017, the cave-in occurred in Huabing Dressing Plant, forming a subsidence pit about $40 \mathrm{~m}$ deep, which caused the whole plant to fall into the ground, causing huge economic losses. From April to May, 2019, two consecutive goaf ground collapses occurred in the No. 3 mining area about $90 \mathrm{~m}$ away from Zhoutaizi Village, with a depth of about $40 \mathrm{~m}$ and a diameter of about $50 \mathrm{~m}$, resulting in mine road damage and broken connection. The potential safety hazard of the collapse poses a great threat to the surrounding buildings and residential areas. Therefore, it is an important guarantee to carry out the stability analysis of the goaf and guide the safety production of mines to accurately explore the morphological and scale characteristics of the latent goaf.

The study area in this paper is the goaf outside the collapse range of the third mining area. After drilling the goaf, C-ALS 3D laser scanning is adopted to obtain data point cloud and build $3 \mathrm{D}$ visual model, which is imported into FLAC3D to calculate and analyze the stability of the goaf. The actual picture of goaf collapse is as shown in the picture 3 .

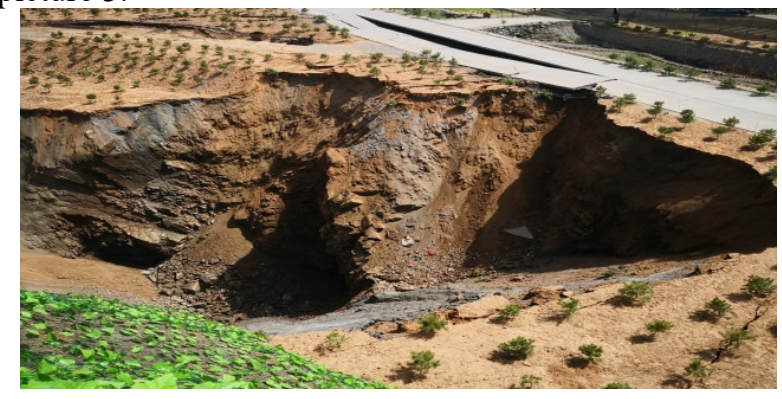

Fig. 3. Goaf Collapse Photo of No. 3 Mining Area

\section{Coupling analysis of cavity precision detection and modeling}

\subsection{Three-dimensional laser measurement (C- ALS) detection}

The original data collected by field measurement is the detection results of point cloud data, as shown in Figure 57 below. The three-dimensional spatial information of the cavity is shown in Table 1.

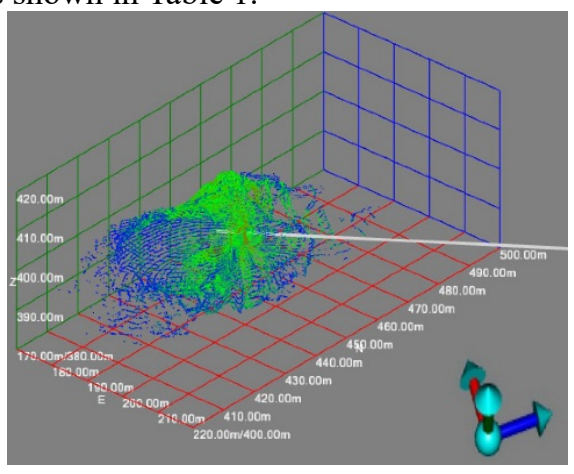

Fig. 4. Global View of point cloud data 


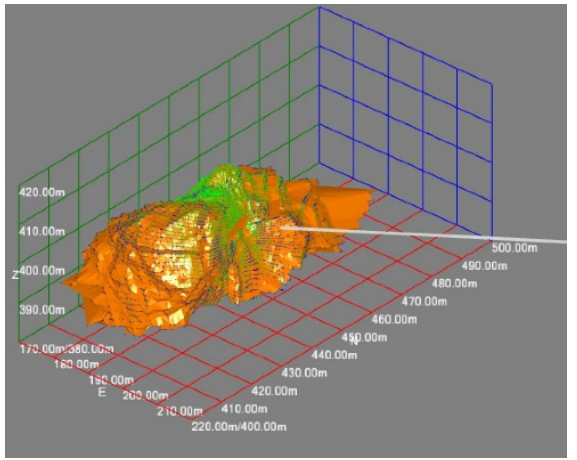

Fig. 5. Preliminary solid model overall model display diagram

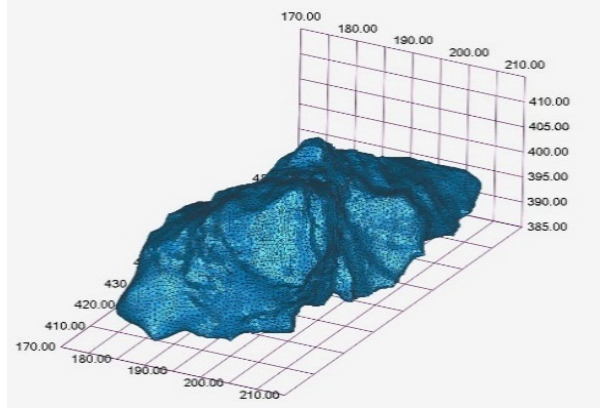

Fig. 6. Overall display of accurate cavity data model

Table 1. Statistics of basic data of cavity

\begin{tabular}{|l|c|c|c|c|}
\hline $\begin{array}{c}\text { The main } \\
\text { parameters }\end{array}$ & parameter & $\begin{array}{c}\text { The starting } \\
\text { point } \\
\text { coordinates }\end{array}$ & $\begin{array}{c}\text { Coordinates } \\
\text { the finish }\end{array}$ & $\begin{array}{c}\text { The } \\
\text { length } \\
\text { of the }\end{array}$ \\
\hline \multirow{2}{*}{$\begin{array}{c}\text { The spatial } \\
\text { distribution } \\
\text { distribution }\end{array}$} & 385.05 & 413 & $27.95 \mathrm{~m}$ \\
\cline { 2 - 5 } & $\begin{array}{c}\text { The X axis } \\
\text { distribution }\end{array}$ & 4539171.93 & 4539208.54 & $36.60 \mathrm{~m}$ \\
\hline $\begin{array}{l}\text { The Y axis } \\
\text { distribution }\end{array}$ & 39548409.48 & 39548478.45 & $68.97 \mathrm{~m}$ \\
\hline $\begin{array}{l}\text { The volume } \\
\text { of space }\end{array}$ & \multicolumn{4}{|c|}{$20097.6 \mathrm{~m}^{3}$} \\
\hline
\end{tabular}

\subsection{Establishment of FLAC3D goaf model}

Based on the C-ALS 3D laser scanning data of borehole, a 3D numerical calculation model of the goaf was established. The depth of the model is $447 \mathrm{~m} \sim 350 \mathrm{~m}$. According to the buried depth and distribution range of the goaf, the size of the calculation model is determined to be $140 \mathrm{~m} \times 160 \times 97 \mathrm{~m}$. The model grid contains a total of 160,280 units, which are mixed by hexahedral and tetrahedral units. A total of 80,749 grid nodes are divided, as shown in Fig 7 and Fig 8 .

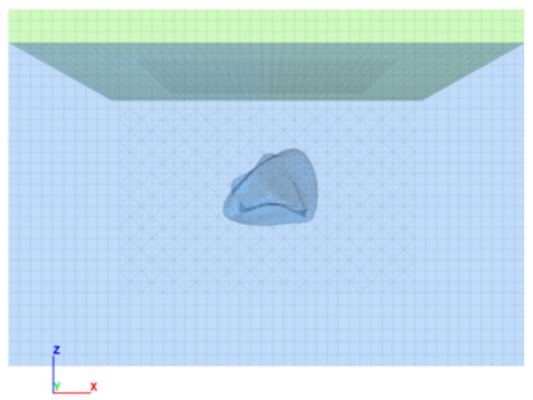

Fig. 7. Face view of goaf

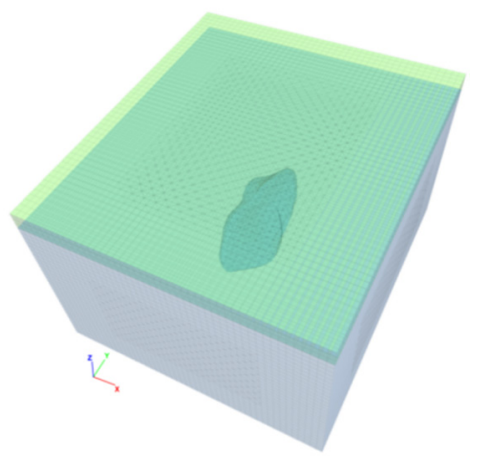

Fig. 8. Three-mode model diagram of goaf

\subsection{Boundary conditions and parameters of the model}

All models adopt solid element simulation, and it is assumed that the failure of rock and soil material conforms to the Mohr-Coulomb strength criterion. The boundary conditions of the calculation model are as follows: the side is restricted to horizontal movement, the bottom is fixed, and the upper surface of the model is free boundary. The required mechanical parameters are calculated and the results of physical and mechanical experiments are as follows:

Table 2. Physico-mechanical parameters of geomaterials

\begin{tabular}{|c|c|c|c|c|c|c|c|}
\hline $\begin{array}{c}\text { The } \\
\text { serial } \\
\text { num } \\
\text { ber }\end{array}$ & $\begin{array}{c}\text { The } \\
\text { litholog } \\
\mathbf{y} \text { name }\end{array}$ & $\begin{array}{c}\text { Bulk } \\
\text { dens } \\
\text { ity } \\
\mathbf{/ k g} / \\
\mathbf{m}^{\mathbf{3}}\end{array}$ & $\begin{array}{c}\text { Modulus } \\
\text { of } \\
\text { elasticity/ } \\
\text { GPa }\end{array}$ & $\begin{array}{c}\text { Poisso } \\
\mathbf{n} \text { 's } \\
\text { ratio }\end{array}$ & $\begin{array}{c}\text { Tensi } \\
\text { se } \\
\text { stren } \\
\text { gth } \\
\text { /MPa }\end{array}$ & $\begin{array}{c}\text { Cohes } \\
\text { ive } \\
\text { force } \\
\text { /MPa }\end{array}$ & $\begin{array}{c}\text { Angl } \\
\text { e of } \\
\text { inter } \\
\text { nal } \\
\text { fricti } \\
\text { on/ }\end{array}$ \\
\hline 1 & $\begin{array}{c}\text { Roof } \\
\text { surroun }\end{array}$ & 2700 & 19.00 & 0.30 & 3.75 & 2.50 & 55 \\
\hline 2 & $\begin{array}{c}\text { Floor } \\
\text { rock }\end{array}$ & 2900 & 25.43 & 0.23 & 3.34 & 3.50 & 65 \\
\hline 3 & $\begin{array}{c}\text { magneti } \\
\text { te }\end{array}$ & 3270 & 29.27 & 0.27 & 3.38 & 4.20 & 70 \\
\hline 4 & $\begin{array}{c}\text { Filling } \\
\text { bodv }\end{array}$ & 1830 & 0.57 & 0.25 & 0.31 & 0.56 & 60 \\
\hline
\end{tabular}

\section{Stability analysis of goaf}

\subsection{Ground pressure distribution law analysis}

Mining activities will cause stress release and stress redistribution in surrounding rock. The distribution of 
major stress in surrounding rock at each horizontal section of the mining area model is shown in the figure below.
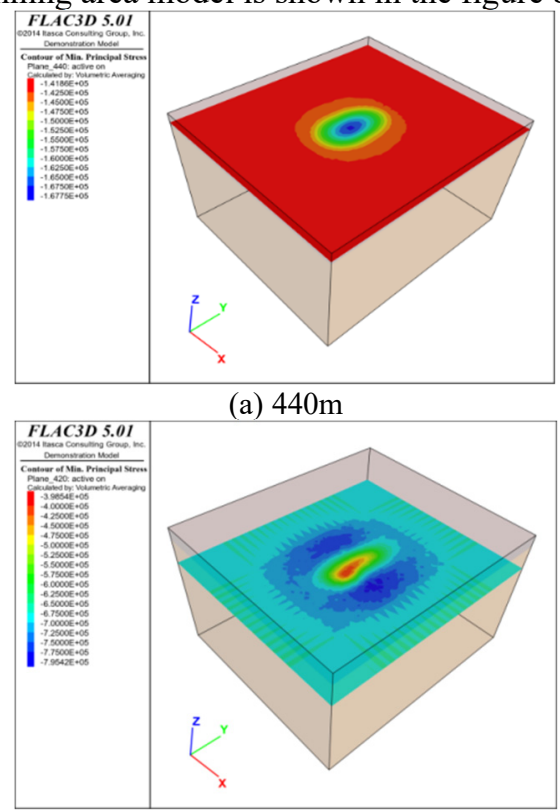

(b) $420 \mathrm{~m}$

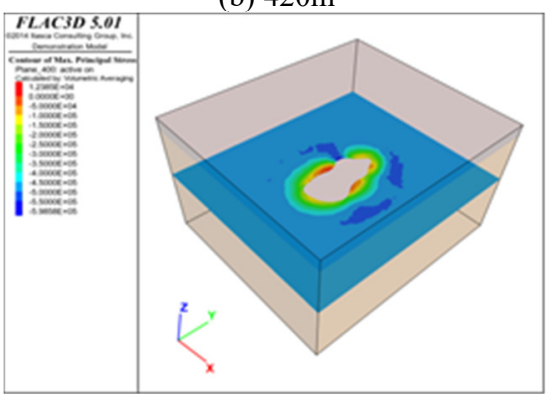

(c) $440 \mathrm{~m}$

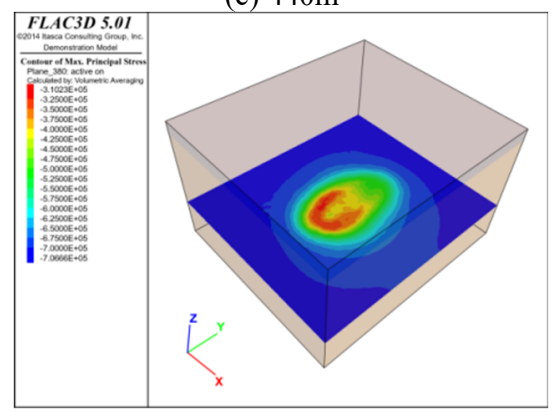

(d) $420 \mathrm{~m}$

Fig. 9. Distribution of horizontal ground pressure in mining

As can be seen from Fig. 9 of ground pressure distribution, the stress field around the goaf evolves continuously with the mining operation. For the calculation model, the horizontal profile is cut every $10 \mathrm{~m}$ height to output the surrounding rock principal stress. It can be seen from the stress distribution of each horizontal surrounding rock that the side wall is mainly dominated by compressive stress, with the maximum compressive stress of 4.61MPa. The concentration area of compressive stress is mostly at the corner of the side wall of the goaf. On the whole, the range of the maximum tensile stress in the pillar and rock is relatively small, which has little influence on the overall stability of the whole goaf.

\subsection{Analysis of deformation distribution characteristics}

The stress release and redistribution of surrounding rock caused by ore-body mining will lead to the deformation of surrounding rock. Similarly, a horizontal profile is cut every $10 \mathrm{~m}$ elevation to output the overall deformation of surrounding rock as shown in Fig.10. It can be seen from the figure that the maximum deformation thickness of the surrounding rock in the mining area is less than $1 \mathrm{~mm}$, indicating that the surrounding rock is relatively hard and no large-scale deformation disaster accident will occur, but rock fall and roof caving may occur in a small range.

This is consistent with the fact that no obvious surface deformation was found at the site, but the deformation activity of the newly formed goaf in the lower part should be paid more attention to to prevent the tensile failure of the roof resulting in collapse and roof caving.

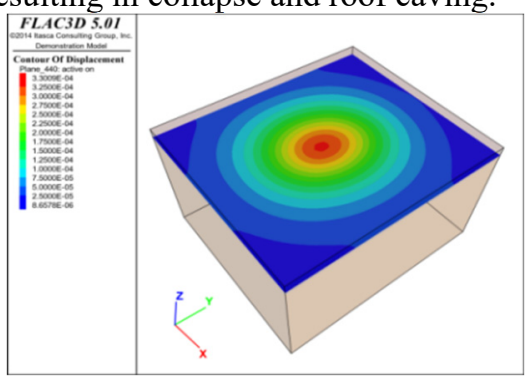

(a) $440 \mathrm{~m}$

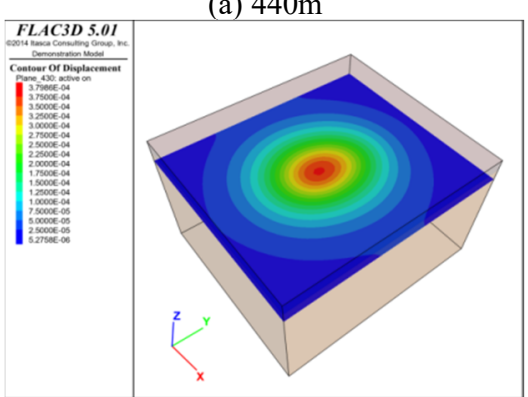

(b) $420 \mathrm{~m}$

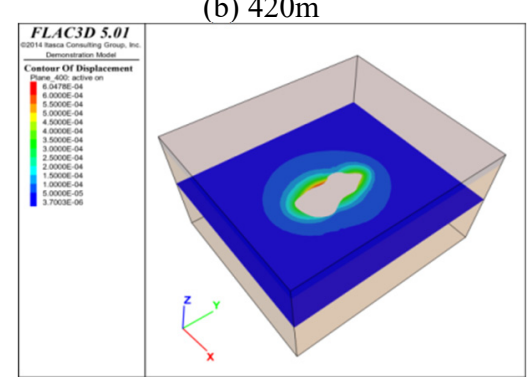

(c) $440 \mathrm{~m}$

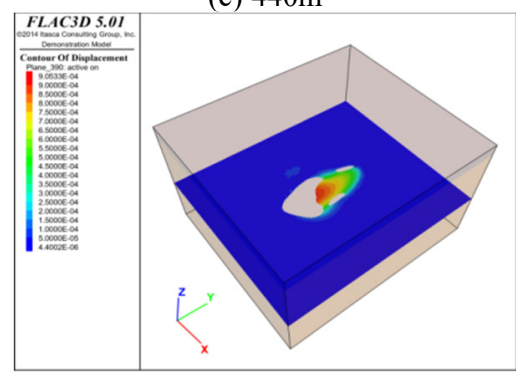

(d) $420 \mathrm{~m}$

Fig. 10. The Deformation distribution of surrounding rock in horizontal orebody mining 


\subsection{Distribution characteristics of surface subsidence}

After the mined-out areas are formed by ore-body mining, the surface subsidence of the mined-out areas will be intensified under the action of surface load under longterm exposure. The surface subsidence is shown in Figure 11. According to the simulation results, with the mining of the ore body in the lower part of the mine, a subsidence center is formed above the goaf group, which is consistent with the plane distribution of the goaf. The maximum surface settlement is generally small, and the maximum surface settlement in the goaf area is less than $0.28 \mathrm{~mm}$, that is, the ore body mining has little influence on the surface deformation. The stratum in the mining area is hard and stable, and the goaf is buried deep, so the goaf activity has little influence on the surface, which is consistent with the actual site.

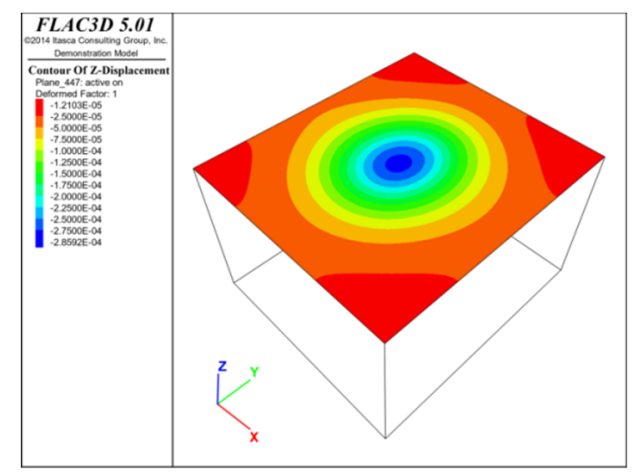

Fig. 11 . Distribution of surface subsidence in mining area

\section{Conclusion}

(1) Through C-ALS 3D laser scanning, the goaf is $68.97 \mathrm{~m}$ in length, $36.60 \mathrm{~m}$ in width, $27.95 \mathrm{~m}$ in height and $20,997.6 \mathrm{~m}^{3}$ in volume.

(2) The maximum deformation thickness of the surrounding rock in the mining area is less than $1 \mathrm{~mm}$, which indicates that the surrounding rock is relatively hard and no large-scale deformation disaster accident will occur. Most of the maximal deformation occurs in the side wall of surrounding rock, and a small range of lamination may occur. In the later production process, the deformation activity of the newly formed goaf in the lower part should be paid more attention to, and the roof tensile failure should be avoided, which may lead to collapse and roof collapse.

(3) The distribution of horizontal failure units at 390m in the goaf is concentrated, while the vertical section shows that there are a few tensile failure units in the floor. Under the influence of many factors such as the exposed roof area, the size of the goaf, the form of the goaf, the burial depth and the surrounding goaf, with the stress evolution, the local failure area may still appear in the surrounding rock, and the subsequent mining activities should be filled in time according to the requirements.

(4) The surface subsidence caused by the mining work of each ore body is generally small, and the maximum surface subsidence is less than $0.28 \mathrm{~mm}$. The stratum in the mining area is hard and stable, and the buried depth of the goaf is deep. Therefore, the goaf activities have little influence on the surface.

\section{References}

1. WANG Shu-ren, JIA Hui-hui, WU Chong-fu. Determination method of roof safety thickness in the mined-out regions under dynamic loading and its application[J], JOURNAL OF CHINA COAL SOCIETY, 2010, 35 (8): 1263-1268. (in Chinese)

2. WANG Shuren, JIA Huihui. Analysis of Creep Characteristics of Shallow Mined-out Areas Roof under Low Stress Conditions [J]. Applied Mechanics and Materials, 2012, Vol. 105-107: 832-836.

3. ZHANG jian wen,WANG Shuren, JIA Huihui. Analysis on Construction Loading at Surface Ground to Roof Deformation Failure Effect in Goaf of Underground Mining[J]. Coal Science and Technology,20102010, 38(9): 19-22. (in Chinese)

4. Wang Changjun, Hao Yanmian. Study on Separated Strata Mechanism in Coal Mine[J]. Coal Technology, 2008, 27(5). (in Chinese)

5. ZhaoDeshen, Xu Tao, Liu Wensheng, et al.. Calculation of Bed Separation under Horizontally and Generally Inclined Coal Seam Mining [J]. Chinese Journal Rock Mechanics and Engineering, 2005, 24 (Supp.2): 5767-5772. (in Chinese)

6. Zhang Baisheng, Kang Lixun, Yang Shuangsuo. Numerical Simulation on Roof Separation and Deformation of Full Seam Roadway wit h St ratified Roof and Large Section [J]. Journal of Mining \& Safety Engineering, 2006, 23 (3): 264-267. (in Chinese)

7. Lu Tingkan, Liu Yuzhou, Yu Haiyong. Separation on Characteristics and Mechanisms of Laminated Composite Roof Strata of Longwall Roadway.Chinese Journal Rock Mechanics and Engineering,2005 , 24(Supp.1):4663- 4669. (in Chinese)

8. Xie Jin hong. Roadway protection techunology along goaf of Layered roofin Inclined thick coal layer[J], Coal Science and Technology. 2015, 43(Supp) :70-72. (in Chinese)

9. LIChang-quan,QIwen-ge.Numerical Researchon Mechanism of Roof Fallng of Stratified Roof[J]. JOURNAL OF WUHAN UNIVERSITY OF TECHNOLOGY, 2008, 30(3) :95- 98. (in Chinese)

10. Tien Y. M., Kuo M. C. Juang C. H. An experimental investigation of the failure mechanism of simulated transversely isotropic rocks[J]. International Journal of Rock Mechanics and Mining Sciences, 2006, 43(8): 1163-1181.

11. Nomikos P. P., Sofianos A. I., Tsoutrelis C. E.. Structural response of vertically multi-jointed roof rock beams[J]. International Journal of Rock Mechanics \& Mining Sciences. 2002, 39(1): 79-94.

12. Wang S R, Jia H H, Chang M S. Analytical Solution 
of the Roof Safe Thickness of the Mined-out Areas under Dynamic Loading [A]. The 2nd International Conference on Mechanic Automation and Control Engineering[C], 15-17 July, 2011, Inner Mongolia, China. Published by IEEE: 1969-1972.

13. Zhang Yucheng, Yang Guanghua, Liu Peng. An Equivalent Approach for Acting Blasting Load in Dynamic Numerical Simulation of Blasting Vibration[J]. Chinese Journal of Underground Space and Engineering, 2012, 8(1) :56- 54. (in Chinese)

14. SHUXi-gang, LIU Xin-rong, JIANG De-yi, Test and Analysis on Blasting Seismic Wave of Geleshan LimestoneMine[J]. Chinese Journal of Underground Space and Engineering, 2008, 4(3) :586- 590. (in Chinese) 